\title{
MODELO DE ZONEAMENTO DE RISCO DE INCÊNDIOS PARA UNIDADES DE CONSERVAÇÃO BRASILEIRAS: O CASO DO PARQUE ESTADUAL DO CERRADO (PR)
}

\author{
Letícia Koproski $^{1}$, Matheus Pinheiro Ferreira ${ }^{2}$, Johann Georg Goldammer ${ }^{3}$, Antonio Carlos Batista ${ }^{4}$ \\ ${ }^{1}$ Médica Veterinária, Dr ${ }^{\mathrm{a}}$., UFPR, Curitiba, PR, Brasil - leticia@koproski.com \\ ${ }^{2}$ Eng. Florestal, Mestrando em Sensoriamento Remoto, INPE, São José dos Campos, SP, Brasil - mpferreira3@googlemail.com \\ ${ }^{3}$ Eng. Florestal, Dr., Global Fire Monitoring Center (GFMC), Max Planck Institute for Chemistry, c/o Albert-Ludwigs-Universität \\ Freiburg/United Nations University (UNU), Freiburg, Alemanha - johann.goldammer@ fire.uni-freiburg.de \\ ${ }^{4}$ Eng. Florestal, Dr., Depto. Ciências Florestais, UFPR, Curitiba, PR, Brasil - batistaufpr@ufpr.br
}

Recebido para publicação: 14/10/2010 - Aceito para publicação: 31/05/2011

\begin{abstract}
Resumo
Este trabalho teve como objetivo estabelecer um modelo de zoneamento de risco de incêndios pela análise dos fatores físicos, associados às fontes de ignição e aos fatores de propagação dos incêndios, que pudesse ser aplicado à realidade da gestão das áreas protegidas em território brasileiro. Para tanto, o Parque Estadual do Cerrado foi selecionado como área de estudo. Foram produzidos mapas de riscos referentes à cobertura vegetal $(\mathrm{V})$, influências humanas $(\mathrm{H})$, declividade $(\mathrm{D})$, orientação das encostas (E) e altimetria (A). O zoneamento foi gerado pela superposição dos mapas de risco, em função da somatória ponderada dos riscos parciais, representado pela equação: RISCO: $4 \mathrm{~V}+3 \mathrm{H}+1 \mathrm{D}$ $+1 \mathrm{E}+1 \mathrm{~A}$. A partir do zoneamento, foi possível identificar duas áreas prioritárias para o manejo do fogo com relação ao risco de incêndios na Unidade. O modelo de integração traduziu adequadamente os níveis de risco e pode ser aplicado em outras unidades de conservação, especialmente em locais onde não existam muitos dados disponíveis sobre o histórico do fogo, ou onde existam poucos dados disponíveis sobre as áreas de estudo. Recomenda-se a utilização do modelo em locais onde não existam diferenças climáticas significativas.

Palavras-chave: Mapas de risco; incêndios florestais; SIG; proteção florestal; áreas protegidas.
\end{abstract}

\begin{abstract}
Fire risk mapping for Brazilian protected areas: the case of Cerrado State Park (PR). The aim of this research was to develop a model of forest fire risk map for Brazilian protected areas. The Cerrado State Park, located in Jaguariaíva city, State of Paraná, south of Brazil, was the focused area. The fire risk map was built up through the integrated analysis of vegetation cover (V), slope gradient (G), slope aspect (A), elevation (E), and human activities (H). For this analysis the Geographical Information System (GIS) was used. The fire risk map was the result of the overlay of the preliminary risk maps, by the model represented by the equation: RISK: $4 \mathrm{~V}+3 \mathrm{H}+1 \mathrm{G}+1 \mathrm{~A}+1 \mathrm{E}$. The results presented that the integration model worked successfully for the area, properly managing the variables according to local characteristics and indicated two priority fire management areas in the Park. The model can be applied to protected areas with few data about fire history or few data about the area itself. The model is not recommended to be used in areas with significantly different climates.

Keywords: Fire risk map; wildfires; GIS; forest protection.
\end{abstract}

\section{INTRODUÇÃO}

Os zoneamentos de risco de incêndios são instrumentos que podem ser utilizados no planejamento da prevenção e do controle de incêndios (FERRAZ; VETTORAZZI, 1998). Eles podem ser aplicados em áreas privadas, unidades de conservação e até mesmo em nível municipal, desde que as variáveis locais que influenciam os riscos de incêndio sejam corretamente consideradas (RIBEIRO et al., 2008).

Os zoneamentos de risco proporcionam uma visualização da distribuição espacial do risco de incêndio em toda a área protegida (OLIVEIRA, 2002), identificando as regiões com maior e menor 
probabilidade de ocorrência de incêndio (VETTORAZZI; FERRAZ, 1998). O risco é determinado pela correlação entre diversas variáveis ambientais, que influenciam a ignição e a propagação do fogo e que, quando associadas, criam condições que dificultam o seu controle. A visão integrada é importante, pois a análise isolada de cada fator não traduz os níveis de risco a que toda a unidade está submetida.

De acordo com Ferraz e Vettorazzi (1998), com as informações obtidas pelo zoneamento, medidas preventivas podem ser tomadas para se reduzir a ocorrência de incêndios e a extensão das áreas atingidas, tais como maior vigilância nas áreas de maior risco, restrição de acesso aos locais de risco elevado, construção de aceiros preventivos e aplicação de técnicas de redução de material combustível nas zonas de maior risco (OLIVEIRA et al., 2002).

O zoneamento também fornece auxílio ao combate, já que as informações obtidas oferecem suporte ao planejamento de construção de estradas de acesso rápido aos locais de maior risco e possibilitam a alocação de recursos de combate em pontos estratégicos. Por fim, os zoneamentos fornecem subsídios para a adequação e distribuição dos recursos e equipamentos destinados à prevenção e ao combate, de acordo com o nível de risco de incêndio (OLIVEIRA, 2002; CARRÃO et al., 2002).

O zoneamento de risco é resultante da integração de duas etapas: elaboração dos mapas de risco e elaboração do zoneamento propriamente dito. Esses dados são manipulados em um Sistema de Informações Geográficas (SIG), que, para Vettorazzi e Ferraz (1998), consiste em uma técnica indispensável no zoneamento de risco de incêndio, pois viabiliza a aplicação prática do mapeamento de risco.

Os mapas de risco são elaborados a partir de mapas temáticos (BATISTA, 2000). Segundo Vettorazzi e Ferraz (1998), dados provenientes de fotografias aéreas, imagens de satélite e até mesmo informações levantadas em condições de campo podem ser utilizados para a elaboração de mapas temáticos referentes à área de estudo. São exemplos de mapas temáticos: mapa de uso do solo, cobertura vegetal, hidrografia e vias de acesso.

O zoneamento de risco de incêndios é gerado pela superposição dos mapas de risco, em função de uma somatória ponderada dos riscos parciais de cada variável previamente analisada (BATISTA, 2000; OLIVEIRA et al., 2004). Diversos modelos de integração têm sido utilizados para a elaboração de zoneamentos de risco de incêndios (CHUVIECO; CONGALTON, 1989; CASTAÑEDA, 1997; FERRAZ; VETTORAZZI, 1998; FREIRE et al., 2002). Para Oliveira (2002), o melhor modelo de ponderação é aquele definido de acordo com as condições de ocorrência dos incêndios locais e que considera a importância de cada variável em função das características da área de estudo.

As variáveis normalmente avaliadas em zoneamentos de risco de incêndio, por apresentarem forte influência na propagação do fogo, são material combustível, condições climáticas, tipo de cobertura vegetal e topografia. A influência das atividades humanas está associada intimamente com o risco de ignição, e dessa forma também é uma variável de risco de grande importância para a elaboração de zoneamentos de risco de incêndio (BATISTA et al., 2002).

No Brasil, o fogo é uma ameaça constante à proteção das unidades de conservação. No entanto, poucas unidades possuem planos de prevenção e controle de incêndios com zoneamentos de risco estabelecidos, ou até mesmo o registro de informações básicas, como o histórico das ocorrências de fogo. De fato, poucas unidades possuem planos de manejo que apresentem informações sobre a unidade e que identifiquem zonas prioritárias de gestão, além de medidas de prevenção e de controle de acidentes ambientais.

Embora o cerrado seja um ecossistema dependente do fogo, a ocorrência de incêndios no Parque Estadual do Cerrado poderia ser um evento catastrófico, principalmente devido às suas dimensões. No caso da ocorrência de um incêndio, os seus 430 hectares poderiam ser rapidamente consumidos, o que produziria diversos impactos sobre a fauna e a flora locais, levando a perdas expressivas da diversidade biológica. Apesar de apresentar plano de manejo, o Parque não possui plano de prevenção e controle de incêndio e o registro oficial das ocorrências de fogo na unidade. Sendo assim, medidas de prevenção, como a elaboração do zoneamento de risco de incêndio, devem ser adotadas para que, em caso de incêndio, a extensão dos danos possa ser minimizada. Dessa forma, estabeleceram-se as seguintes hipóteses de trabalho, considerando as características do Parque:

a) o modelo de integração proporciona a avaliação da distribuição espacial do risco de incêndio e traduz os níveis de riscos obtidos para o Parque Estadual do Cerrado;

b) o modelo de zoneamento de risco de incêndio pode ser aplicado à realidade da gestão das áreas protegidas em território brasileiro. 


\section{MATERIAL E MÉTODOS}

\section{Área de estudo}

O Parque Estadual do Cerrado representa o limite meridional de distribuição geográfica do ecossistema cerrado. É o último remanescente efetivamente protegido desse ecossistema, sob a forma de Unidade de Conservação, no estado do Paraná (STRAUBE et al., 2005). O Parque possui área total de 430 hectares e está localizado na mesorregião centro oriental do Paraná, município de Jaguariaíva, nas coordenadas $24^{\circ} 10^{\prime} \mathrm{S}$ e $49^{\circ} 39^{\prime} \mathrm{W}$. As coordenadas centrais aproximadas no Sistema de Projeção Cartográfica UTM, Datum SAD-69 Zona 22S, são: 7325927 m e 635701 m (Figura 1). A região em que o Parque está inserido recebe influências tanto do clima subtropical úmido mesotérmico (Cfa) quanto do clima temperado propriamente dito $(\mathrm{Cfb})$, e a altitude média é de $810 \mathrm{~m}$. Como o próprio nome da unidade sugere, ela situa-se em área de vegetação clássica de cerrado, representado por suas distintas fitofisionomias. A fauna da região, zoogeograficamente, pertence à Província Guarani (PAIVA, 1999). O Parque abriga 40 espécies de mamíferos, 270 de aves, 45 de répteis e 22 de anfíbios (INSTITUTO AMBIENTAL DO PARANÁ - IAP, 2002).

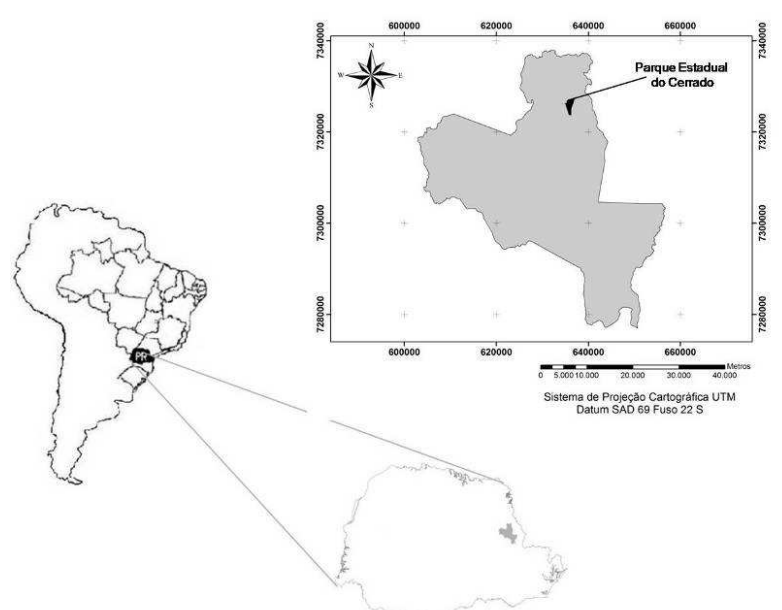

Figura 1. Mapa da localização geográfica do Parque Estadual do Cerrado.

Figure 1. Map of Cerrado State Park location.

\section{Mapas de risco}

Os mapas temáticos foram confeccionados a partir de informações georreferenciadas contidas no banco de dados digital, estabelecido pelo IAP, no ato da elaboração do plano de manejo da unidade. Os dados referentes à vegetação, acessos, infraestrutura, declividade do terreno, altimetria, uso do solo, hidrografia e exposição solar deram origem aos mapas temáticos de cobertura vegetal, influências humanas, declividade, orientação das encostas e altimetria.

Os mapas de risco, por sua vez, foram elaborados com base nos mapas temáticos referentes a fatores ambientais que possuem estreitas ligações com a ignição e a propagação de incêndios, e que mais se ajustaram às características locais do Parque Estadual do Cerrado. Dessa forma, foram confeccionados mapas de risco segundo a cobertura vegetal, influências humanas, declividade, orientação das encostas e altimetria. Toda a análise espacial e a produção cartográfica foram produzidas utilizando-se sistemas de informações geográficas com o auxílio do programa ArcGIS - versão 9.

\section{Cobertura vegetal}

Os tipos de cobertura vegetal foram distribuídos em classes de risco, segundo a sua vulnerabilidade ao fogo. Essas classes correspondem aos riscos baixo, moderado, alto e muito alto. Para cada uma das classes foi atribuído um coeficiente referente ao nível de risco, o qual foi a base para a elaboração do mapa final de zoneamento de risco de incêndio para o Parque Estadual do Cerrado. Na tabela 1 estão representadas as relações entre o tipo de cobertura vegetal, o nível de risco de incêndio e seus respectivos coeficientes. 
Tabela 1. Classificação do risco de incêndio segundo a cobertura vegetal.

Table 1. Vegetation cover fire risk ranking.

\begin{tabular}{lcc}
\hline Cobertura vegetal & Risco & Coeficiente \\
\hline Floresta de galeria ciliar, floresta ecotonal, floresta ecotonal alterada, área antropizada & Baixo & 1 \\
Campo higro-hidrófilo, afloramento rochoso & Moderado & 2 \\
Cerrado stricto sensu & Alto & 3 \\
Campo sujo, campo cerrado, campo cerrado alterado & Muito alto & 4 \\
\hline
\end{tabular}

As fitofisionomias associadas à formação vegetacional de cerrado foram classificadas como sendo de risco de incêndio mais elevado do que as demais fitofisionomias encontradas no Parque. Devido à maior presença de gramíneas e sua maior inflamabilidade, o campo sujo, o campo cerrado e o campo cerrado alterado foram classificados em maior grau de risco do que o cerrado stricto sensu. A área antropizada foi classificada como baixo risco de incêndio, devido à pouca cobertura vegetal observada no local. Floresta de galeria ciliar, floresta ecotonal e floresta ecotonal alterada também foram classificadas como baixo risco de incêndio, em função da maior umidade esperada para esses locais. Apesar da umidade existente no solo, o campo higro-hidrófilo foi classificado como risco moderado, assim como o afloramento rochoso, devido ao acúmulo de material combustível observado in loco nessas fisionomias.

Influências humanas

O mapa de risco segundo as influências humanas representa todas as atividades realizadas no Parque, considerando a infraestrutura existente na qual a vegetação sofre risco de incêndio. Um valor de risco foi atribuído em relação às atividades humanas, de acordo com as distâncias a estradas e zonas urbanas, proposto por Freire et al. (2002) e adaptado pelos autores para as condições locais do Parque Estadual do Cerrado. Nesse caso, foram consideradas as distâncias às estradas, trilhas e edificações localizadas na área. Considerando a extensão do Parque e a resolução dos mapas, o raio de influência definido foi de 30 metros, tanto para estradas quanto para trilhas e edificações. As áreas externas ao raio de influência definido foram classificadas como baixo potencial de risco de incêndio. As áreas sob influência das estradas e edificações foram classificadas como alto risco e as trilhas como muito alto, devido ao tráfego de visitantes e ao maior contato dos mesmos com o meio nesses locais. Para cada classe, atribuiu-se um coeficiente referente ao nível de risco. Na tabela 2 estão classificadas as relações entre as áreas sob influência de atividades humanas, o nível de risco e seus respectivos coeficientes.

Tabela 2. Classificação do risco segundo influências humanas.

Table 2. Human activities fire risk ranking.

\begin{tabular}{lcc}
\hline Atividades humanas & Risco & Coeficiente \\
\hline Fora da área envolvente & Baixo & 1 \\
Dentro da área envolvente - Estradas e edificações & Alto & 3 \\
Dentro da área envolvente - Trilhas & Muito alto & 4 \\
\hline
\end{tabular}

Declividade

Os valores de inclinação do terreno foram distribuídos em cinco classes, de acordo com sua influência na taxa de propagação do fogo, segundo Soares (1985). Para cada classe foi atribuído um coeficiente referente ao nível de risco. Na tabela 3 estão representadas as relacões entre o grau de inclinação do terreno, a taxa de propagação do fogo, o nível de risco de incêndio e seus respectivos coeficientes.

Tabela 3. Classificação do risco segundo a declividade do terreno.

Table 3. Slope gradients fire risk ranking.

\begin{tabular}{lccc}
\hline Inclinação (\%) & Fator de propagação & Risco & Coeficiente \\
\hline Até 15 & 1,00 & Baixo & 1 \\
$16-25$ & 1,05 & Moderado & 2 \\
$26-35$ & 1,15 & Alto & 3 \\
$36-45$ & 1,20 & Muito alto & 4 \\
$\geq 46$ & 1,25 & Extremo & 5 \\
\hline
\end{tabular}


Orientação das encostas

Os níveis de risco em função da orientação das encostas e consequentemente da exposição solar foram distribuídos em cinco classes, de acordo o proposto para o hemisfério Sul, por Ferraz e Vetorazzi (1998). Para cada classe foi atribuído um coeficiente referente ao nível de risco. Na tabela 4 estão representadas as relações entre o ângulo de orientação, a exposição solar, o nível de risco e seus respectivos coeficientes.

Tabela 4. Classificação do risco segundo a orientação das encostas.

Table 4. Slope aspects fire risk ranking.

\begin{tabular}{lccc}
\hline Ângulo de orientação & Exposição & Risco & Coeficiente \\
\hline $112,5^{\circ}$ a $247,5^{\circ}$ & $\mathrm{SE} / \mathrm{S} / \mathrm{SW}$ & Baixo & 1 \\
$67,5^{\circ}$ a $112,5^{\circ}$ & $\mathrm{E}$ & Moderado & 2 \\
$22,5^{\circ}$ a $67,5^{\circ}$ & $\mathrm{NE}$ & Alto & 3 \\
$247,5^{\circ}$ a $337,5^{\circ}$ & $\mathrm{NW} / \mathrm{W}$ & Muito alto & 4 \\
$337,5^{\circ}$ a $22,5^{\circ}$ & $\mathrm{N}$ & Extremo & 5 \\
\hline
\end{tabular}

Altimetria

As condições de risco em função da variação da altitude foram distribuídas em cinco classes, de acordo o proposto por Salas e Chuvieco (1994) e adaptado por Batista et al. (2002), para os valores máximos e mínimos de altitude registrados no estado do Paraná. Para cada classe, atribuiu-se um coeficiente referente ao nível de risco. $\mathrm{Na}$ tabela 5 estão representadas as relações entre a classe altimétrica, o nível de risco e seus respectivos coeficientes.

Tabela 5. Classificação do risco segundo a altimetria.

Table 5. Elevation fire risk ranking.

\begin{tabular}{lcc}
\hline Classe altimétrica & Risco & Coeficiente \\
\hline Até $600 \mathrm{~m}$ & Extremo & -1 \\
$600-900 \mathrm{~m}$ & Muito alto & -2 \\
$900-1200 \mathrm{~m}$ & Alto & -3 \\
$1200-1500 \mathrm{~m}$ & Moderado & -4 \\
Acima de $1500 \mathrm{~m}$ & Baixo & -5 \\
\hline
\end{tabular}

\section{Zoneamento de risco de incêndio}

O mapa de zoneamento de risco de incêndio foi oriundo da integração dos mapas de risco segundo a cobertura vegetal, influências humanas, declividade, orientação das encostas e altimetria. Esses mapas foram integrados com o auxílio de um modelo de ponderação que indicou a importância de cada variável para a ocorrência e propagação dos incêndios no Parque, de acordo com a equação adaptada de Freire et al. (2002). Nessa equação, cada variável recebeu um peso de acordo com sua importância para o risco de incêndio, de modo que a somatória dos pesos das variáveis analisadas totalizasse dez pontos, para a validação da análise. A aplicação desse balanceamento na somatória traduz o grau de influência das cinco variáveis analisadas sobre o risco de ignição e propagação dos incêndios no Parque Estadual do Cerrado.

Sendo assim, com base em conceitos de ecologia e comportamento do fogo, a vegetação recebeu o maior peso, pois representa o combustível a ser consumido e sem combustível não há fogo; as influências humanas receberam o segundo maior peso, pois representam a "faísca", ou seja, o fator que iniciará a ignição; e os fatores relacionados com a topografia (declividade, orientação das encostas e altimetria), que são intimamente relacionados com a propagação do fogo, receberam pesos de modo que a somatória dos pesos dessas três variáveis não ultrapassasse o peso atribuído à variável de influências humanas.

O zoneamento foi distribuído em cinco classes de risco, segundo a sua vulnerabilidade ao fogo. Essas classes correspondem aos riscos baixo, moderado, alto, muito alto e extremo. A unidade de análise foi definida em formato raster e disponibilizada como bytes representando pixels $\mathrm{de} 10 \mathrm{~m}^{2}$. O modelo de integração dos dados foi expresso pela equação:

$$
\mathrm{RISCO}=4 \mathrm{~V}+3 \mathrm{H}+1 \mathrm{D}+1 \mathrm{E}+1 \mathrm{~A}
$$


em que: $\quad \mathrm{V}=$ coeficiente de risco segundo a cobertura vegetal;

$\mathrm{H}=$ coeficiente de risco segundo influências humanas;

$\mathrm{D}=$ coeficiente de risco segundo a declividade;

$\mathrm{E}=$ coeficiente de risco segundo a orientação das encostas;

$\mathrm{A}=$ coeficiente de risco segundo a altimetria.

Os valores que poderiam ser obtidos pelas somatórias dos mapas preliminares de riscos variaram entre 4 e 41 pontos e foram distribuídos em cinco classes de risco. Essas classes correspondem aos riscos baixo, moderado, alto, muito alto e extremo. Esses valores foram a base para a elaboração do mapa final de zoneamento de risco de incêndio para o Parque Estadual do Cerrado. Na tabela 6 estão representadas as relacões entre os valores das somatórias dos mapas de risco preliminares e as classes de risco de incêndio.

Tabela 6. Classificação do risco de incêndio segundo a somatória dos mapas de risco preliminares.

Table 6. Fire risk ranking due to the integration of the preliminary risk maps.

\begin{tabular}{lc}
\hline Somatória dos mapas de risco preliminares & Classe de risco \\
\hline $4-10$ & Baixo \\
$11-18$ & Moderado \\
$19-26$ & Alto \\
$27-34$ & Muito alto \\
$35-41$ & Extremo \\
\hline
\end{tabular}

\section{RESULTADOS E DISCUSSÃO}

\section{Cobertura vegetal}

Em relação ao mapa de risco de incêndio segundo a cobertura vegetal, o risco baixo foi registrado em 81,91 ha, distribuindo-se por três fitofisionomias localizadas em sua maioria ao longo dos vales dos rios que delimitam o Parque: floresta de galeria $(6,43 \%)$, floresta ecotonal $(6,21 \%)$ e floresta ecotonal alterada $(5,51 \%)$. A área antropizada $(0,90 \%)$ também foi classificada como baixo risco de incêndio, devido à ausência de vegetação, principalmente ao longo da estrada principal de acesso à unidade. O risco moderado foi registrado nas áreas de campo higro-hidrófilo $(4,61 \%)$ e afloramento rochoso $(11,91 \%)$, correspondendo a 71,03 ha. O risco alto foi registrado na porção central do Parque, nas áreas de cerrado stricto sensu (20,09\%), equivalente a 86,38 ha. O risco de incêndio muito alto foi identificado em 190,49 ha ao longo da porção oeste do Parque, abrangendo áreas de campo sujo (5,86\%), campo cerrado $(15,12 \%)$ e campo cerrado alterado $(23,32 \%)$. O mapa de risco segundo a cobertura vegetal reflete a inflamabilidade da vegetação na área de estudo. Dessa forma, as regiões nordeste e oeste foram identificadas como as mais suscetíveis à ocorrência de incêndios no Parque (Figura 2).

\section{Influências humanas}

O mapa de risco de incêndio em função das influências humanas identificou as áreas das atividades e circulação humanas na área (Figura 3). O risco registrado variou entre três categorias: baixo, alto e muito alto. A maioria da área $(83,78 \%)$, equivalente a 360,35 ha, foi identificada como baixo risco de incêndio em função da baixa circulação de pessoas nesses locais. As áreas próximas às trilhas temáticas existentes no Parque foram classificadas como risco muito alto, devido à circulação de visitantes, e representaram somente 5,42\% da área, correspondente a 23,30 ha. As regiões adjacentes às estradas foram classificadas como nível alto de risco, representando $10,8 \%$ da área, correspondente a 46,35 ha. A inexistência de registros de focos de calor nas propriedades vizinhas identificou o baixo uso do fogo nesses locais, e dessa forma a influência das atividades realizadas nas propriedades vizinhas ao Parque foi considerada como nula para a elaboração do mapa de risco de incêndio segundo atividades humanas.

As áreas classificadas como risco muito alto são identificadas como zonas de uso extensivo no plano de manejo da Unidade (IAP, 2002). Sendo assim, atividades voltadas para o uso público são permitidas nesses locais, tais como recreação, lazer e educação ambiental. Dessa forma, diversas normas para o uso desses locais são regulamentadas no plano de manejo. No entanto, nenhuma delas aborda a 
problemática dos incêndios. Portanto, recomenda-se que atividades de prevenção e vigilância sejam executadas nesses locais. Recomenda-se também a instalação de uma placa indicativa do grau de risco de incêndios no início do trajeto das trilhas, para a informação do risco de incêndio aos visitantes. As áreas classificadas como risco alto, apesar de serem representadas por uma estrada, receberam pesos menores do que as trilhas com relação ao perigo de fogo, pois, de acordo com o plano de manejo, são zonas de uso especial, sendo o acesso e a circulação nesses locais permitidos somente a pessoas autorizadas, diminuindo dessa forma o risco de ignição.

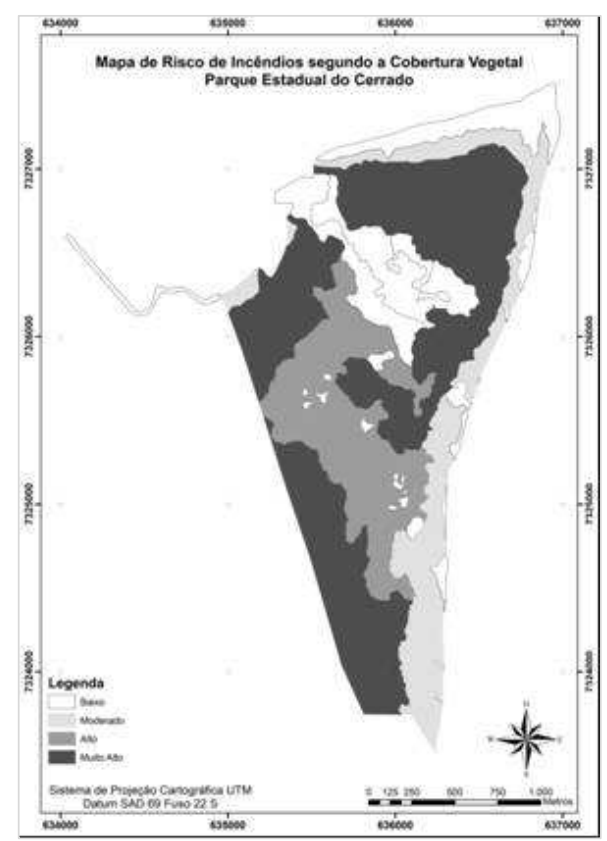

Figura 2. Mapa de risco de incêndio segundo a cobertura vegetal, Parque Estadual do Cerrado. Figure 2. Fire risk map of vegetation cover, Cerrado State Park.

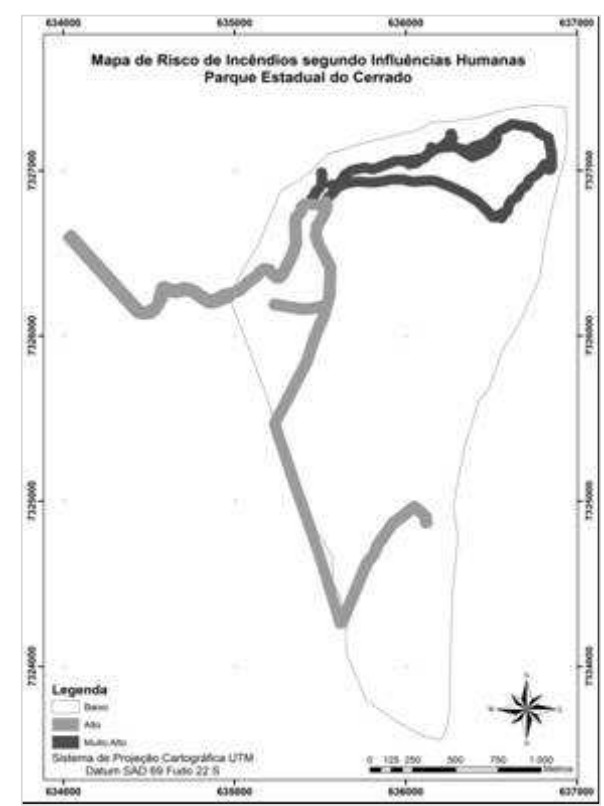

Figura 3. Mapa de risco de incêndio segundo influências humanas, Parque Estadual do Cerrado. Figure 3. Fire risk map of human activities, Cerrado State Park. 


\section{Declividade}

A maior porção do Parque, equivalente a 360 ha $(83,76 \%)$, possui até $15 \%$ de declividade, e por isso apresenta baixo risco de incêndio segundo a declividade, devido à baixa taxa de propagação do fogo nesses locais. Nas faces norte e leste, onde se encontram os vales dos rios que delimitam a área do Parque, intercalam-se porções que correspondem aos riscos de incêndio moderado $(8,19 \%)$, alto $(5,26 \%)$, muito alto $(2,01 \%)$ e extremo $(0,77 \%)$. Alguns fragmentos correspondentes aos níveis moderado e alto também foram observados próximos à sede do Parque (Figura 4).

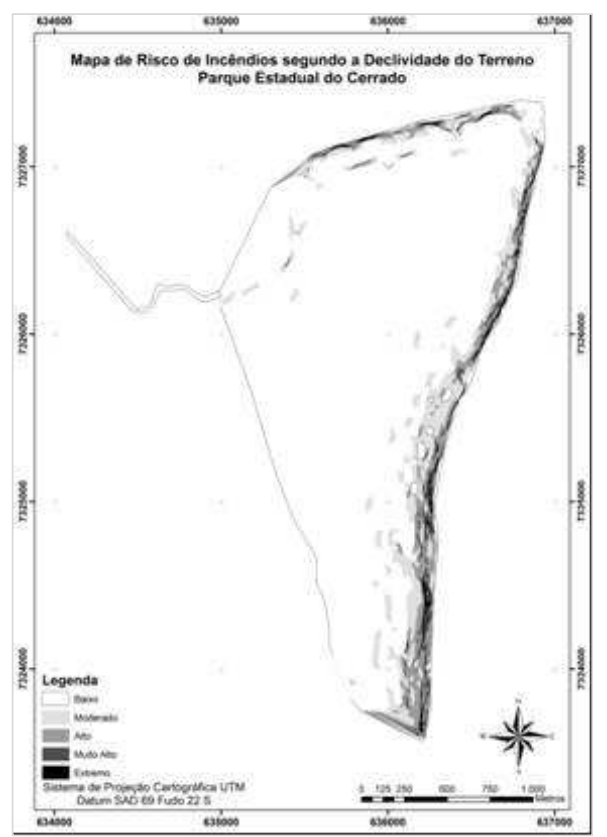

Figura 4. Mapa de risco de incêndio segundo a declividade, Parque Estadual do Cerrado. Figure 4. Fire risk map of slope gradients, Cerrado State Park.

\section{Orientação das encostas}

O mapa de risco de incêndio em função da orientação das encostas representa indiretamente a umidade do material combustível, pois ela é determinada pela taxa de radiação incidente. Esse mapa revelou que 76,96\% da área do Parque foram classificados como risco moderado ou muito alto. $\mathrm{O}$ risco muito alto $(33,73 \%)$, equivalente a 145,03 ha, distribui-se pela porção noroeste, e o risco moderado $(43,23 \%)$, representado por 185,88 ha, distribui-se pelas porções nordeste, sudoeste e sudeste do Parque. Os riscos nulo $(4,23 \%)$, baixo $(6,04 \%)$, alto $(7,60 \%)$ e extremo $(5,16 \%)$ distribuíram-se em pequenos fragmentos pelo Parque (Figura 5).

\section{Altimetria}

De acordo com os dados aferidos em campo no momento da elaboração do plano de manejo da Unidade (IAP, 2002), a altitude no Parque varia de 709 até 911 metros. Dessa forma, a grande maioria do terreno foi classificada como risco de incêndio muito alto, representada por $95,29 \%$, correspondente a 409,74 hectares, e somente $4,71 \%$ da área, localizada na porção oeste e equivalente a 20,26 ha, encontrase na categoria de alto risco de incêndio segundo a variação da altitude. A pequena variação do grau risco segundo a altimetria observada deve-se à pequena variação da altitude registrada para a área (Figura 6). Os mapas de risco referentes à topografia (declividade, altimetria e orientação das encostas) revelaram que no Parque Estadual do Cerrado os combustíveis localizados na região noroeste secam mais rapidamente que os demais e que o fogo tem a tendência de se propagar mais rapidamente nos vales dos rios. 


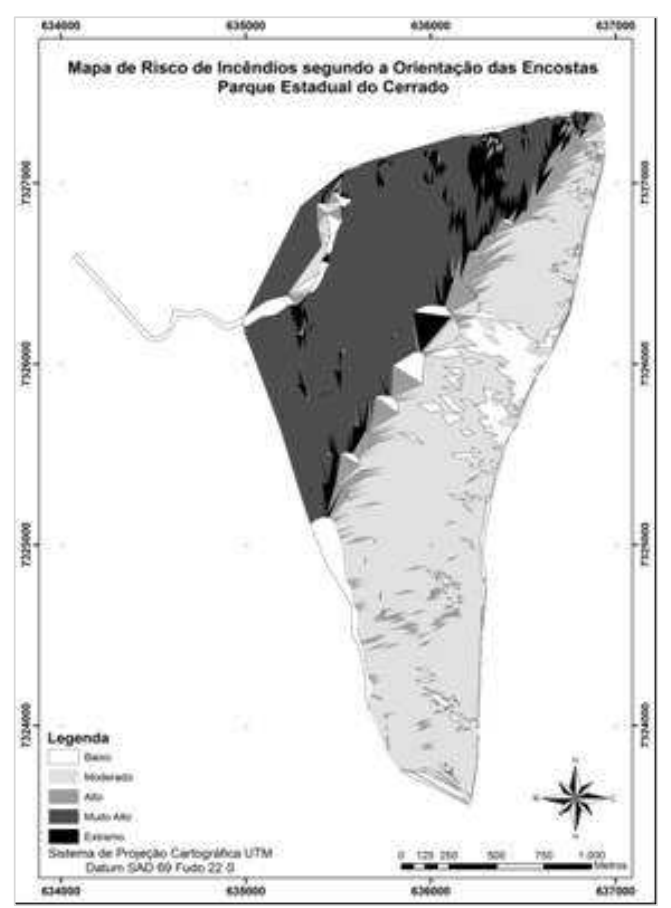

Figura 5. Mapa de risco de incêndio segundo a orientação das encostas, Parque Estadual do Cerrado. Figure 5. Fire risk map of slope aspects, Cerrado State Park.

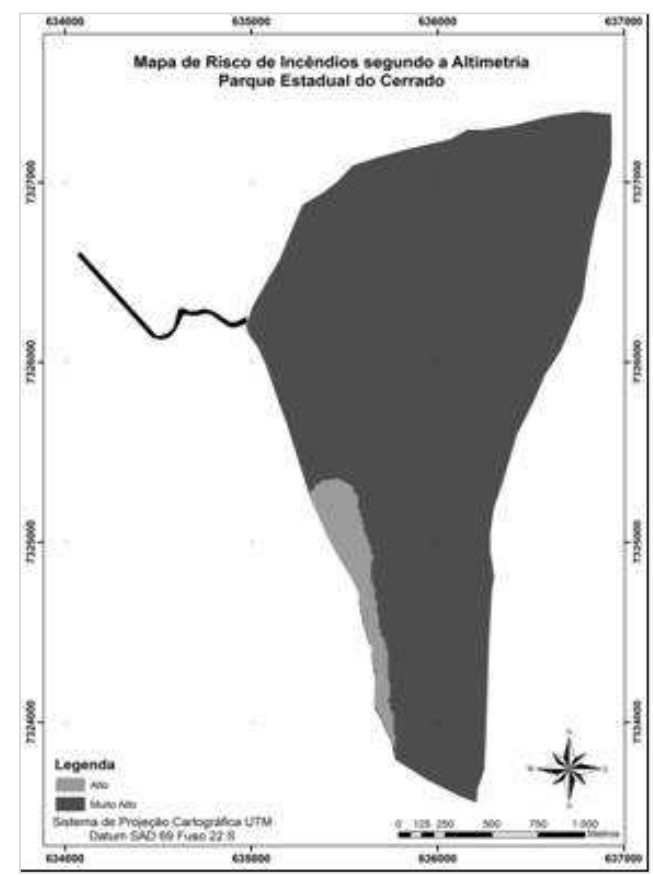

Figura 6. Mapa de risco de incêndio segundo a altimetria, Parque Estadual do Cerrado.

Figure 6. Fire risk map of elevation, Cerrado State Park.

\section{Zoneamento de risco de incêndios}

A integração dos mapas de risco para a elaboração do zoneamento do risco de incêndio para o Parque Estadual do Cerrado permite a visualização global de todos os fatores de risco analisados (Figura 7). A classe de risco baixo $(12,99 \%)$ somou 55,85 ha. O risco baixo distribuiu-se pela floresta ecotonal alterada e por 
porções isoladas ao longo das faces norte, leste e região central. O risco moderado foi observado ao longo das faces norte e leste, pelos vales dos rios Santo Antônio e Jaguariaíva, respectivamente, além de distribuir-se pela porção central da unidade, representando 37,99\%, equivalendo a 163,35 ha. A classe de risco alto foi a que abrangeu a maior porção do Parque, 190,74 ha, representando 44,36\% da área. A classe de risco muito alto foi a menos observada, aparecendo somente em pequenas regiões adjacentes às áreas de risco alto, representando 4,66\%, ou 20,03 ha. Assim como registrado por Ribeiro et al. (2008) em outra área no estado do Paraná, o risco extremo não foi observado no Parque Estadual do Cerrado.

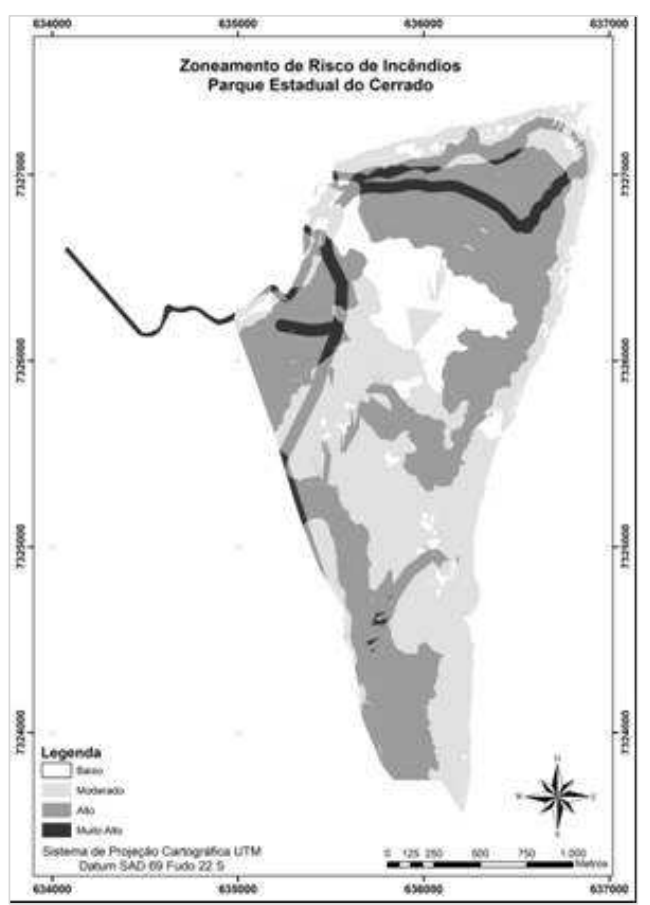

Figura 7. Zoneamento de risco de incêndios do Parque Estadual do Cerrado. Figure 7. Fire risk map of Cerrado State Park.

A partir do zoneamento, foi possível identificar duas áreas prioritárias para o manejo do fogo com relação ao risco de incêndio. A primeira representada pelas áreas de risco alto e muito alto e a segunda representada pelas áreas de risco moderado. A matriz das áreas de risco alto é adjacente aos fragmentos das áreas de risco muito alto e está localizada nas porções nordeste e oeste do Parque, englobando as trilhas temáticas e a estrada de acesso à unidade. Dessa forma, na porção nordeste, atividades de prevenção devem ser constantemente realizadas, por meio de ações formais e informais que envolvam os visitantes. Essas atividades, bem como a fiscalização, devem ser intensificadas nos períodos críticos de incêndios. Recomenda-se que painéis informativos sobre a ecologia do fogo no cerrado sejam instalados no local, bem como uma placa com a indicação diária do grau de risco de incêndio, baseado no cálculo de um índice de perigo, como a Fórmula de Monte Alegre Alterada. Nas regiões próximas à divisa com propriedades vizinhas, na porção oeste do Parque, em que o risco alto e muito alto foi identificado, recomenda-se que as campanhas de prevenção com a comunidade sejam intensificadas nas épocas de maior risco e que as equipes de vigilância e fiscalização acompanhem as atividades de uso do fogo realizadas na vizinhança.

A segunda zona prioritária distribui-se principalmente ao longo dos vales dos rios e pela porção central da unidade. Sendo assim, atividades das equipes de vigilância e fiscalização devem ser realizadas, principamente, nos vales dos rios, e a vigilância por meio da torre de detecção de incêndios deve ser intensificada nos períodos críticos, visando à proteção do núcleo de cerrado da unidade, localizado na porção central do Parque, representado pela classe de risco de incêndio moderado.

Da mesma forma registrada por Ferraz e Vettorazzi (1998), a operação de atribuição dos coeficientes e pesos às variáveis foi considerada a parte mais sensível da avaliação, visto que não existiam 
registros oficiais de ocorrências de incêndios no Parque que pudessem auxiliar o ajuste do método para a área. Acredita-se, assim como observado por Freire et al. (2002) para Portugal, que a existência desse banco de dados históricos teria permitido o desenvolvimento de relações mais robustas entre as variáveis utilizadas na construção do modelo de integração.

\section{CONCLUSÕES E RECOMENDAÇÕES}

- O zoneamento proporcionou a avaliação da distribuição espacial do risco de incêndio para a unidade. O modelo de integração utilizado traduziu adequadamente os níveis de risco obtidos para o Parque Estadual do Cerrado, pois considerou a importância de cada variável em função das características da área de estudo. Além disso, as variáveis selecionadas no modelo são vastamente reconhecidas em relação à sua importância tanto para a ignição (vegetação e influências humanas) quanto para a propagação do fogo (declividade, orientação das encostas e altimetria).

- O modelo de integração utilizado neste estudo pode ser aplicado em outras unidades de conservação, especialmente no caso da realidade brasileira, em que não existem muitos dados disponíveis sobre o histórico do fogo, ou onde existam poucos dados disponíveis sobre as áreas de estudo.

- Recomenda-se a utilização do modelo em áreas sem ocupação humana e em locais onde não existam diferenças climáticas significativas, pois ele não aborda dados de densidade demográfica e também não abrange variáveis meteorológicas, diferentemente dos modelos propostos por Salas e Chuvieco (1994), Ferraz e Vettorazzi (1998) e Oliveira (2002). O zoneamento de risco de incêndios do Parque deve ser atualizado periodicamente, pois as condições ambientais estão em constante mudança e podem modificar o nível de risco ao longo do tempo. Além disso, a escala de valores e a adoção dos pesos para as variáveis utilizadas poderão ser aprimoradas estatisticamente, utilizando-se registros de incêndios e de focos de calor que ocorram na unidade.

\section{AGRADECIMENTOS}

Ao CNPq, pela bolsa de doutorado concedida. À CAPES e ao DAAD, pela bolsa de doutorado sanduíche concedida, processo BEX2098/06-7.

\section{REFERÊNCIAS}

BATISTA, A. C. Mapas de risco: uma alternativa para o planejamento de controle de incêndios florestais. Floresta, Curitiba, v. 30, n. 1/2, p. 45 - 54, 2000.

BATISTA, A. C.; OLIVEIRA, D. S.; SOARES, R. V. Zoneamento de risco de incêndios florestais para o estado do Paraná. Curitiba: FUPEF, 2002. 86 p.

CARRÃO, H.; CAETANO, M.; FREIRE, S.; NUNES, A. Carta de ocupação do solo e avaliação do estado da vegetação com imagens de satélite para prevenção de fogos florestais. In: ESIG, 7., 2002, Oeiras, Portugal. Anais do... Oeiras, Portugal, 2002.

CASTAÑEDA, A. Zonificacion para el manejo de incendios en plantaciones forestales en Colombia. Boletin de Protecion Forestal, Colombia, n. 2, p. 38 - 46, 1997.

CHUVIECO, E.; CONGALTON, R. G. Application of remote sensing and geographic information systems to forest fire hazard mapping. Remote Sensoring of Environment, New York, v. 29, p. 147 - 159, 1989.

FERRAZ, S. F. B.; VETTORAZZI, C. A. Mapeamento de risco de incêndios florestais por meio de sistema de informações geográficas (SIG). Scientia Forestalis, Piracicaba, v. 53, p. 39 - 48, 1998.

FREIRE, S.; CARRÃO, H.; CAETANO, M. Produção de cartografia de risco de incêndio florestal com recurso a imagens de satélite e dados auxiliares. Lisboa: IGP, 2002.

INSTITUTO AMBIENTAL DO PARANÁ (IAP). Plano de manejo: Parque Estadual do Cerrado. Curitiba: IAP, 2002. 179 p. 
OLIVEIRA, D. S. Zoneamento de risco de incêndios em povoamentos florestais no norte de Santa Catarina. 113 f. Dissertação (Mestrado em Engenharia Florestal) - Setor de Ciências Agrárias, Universidade Federal do Paraná, Curitiba, 2002.

OLIVEIRA, D. S.; BATISTA, A. C.; SOARES, R. V.; SLUTTER, C. R. Fire risk mapping for pine and eucalyptus stands in Três Barras, State of Santa Catarina, Brazil. In: FOREST FIRE RESEARCH \& WILDLAND FIRE SAFETY, 4., 2002, Coimbra. Proceedings... Coimbra: ADAI. University of Coimbra, 2002.

OLIVEIRA, D. S.; BATISTA, A. C.; SOARES, R. V.; GRODZKI, L.; VOSGERAU, J. Zoneamento de risco de incêndios florestais para o estado do Paraná. Floresta, Curitiba, v. 34, n. 2, p. 217 - 221, 2004.

PAIVA, M. P. Conservação da fauna brasileira. Rio de Janeiro: Interciência, 1999.

RIBEIRO, L.; KOPROSKI, L. P.; STOLLE, L.; LINGNAU, C.; SOARES, R.; BATISTA, A. C. Zoneamento de riscos de incêndios florestais para a fazenda experimental do Canguiri, Pinhais (PR). Floresta, Curitiba, v. 38, n. 3, p. 561 - 570. 2008.

SALAS, J.; CHUVIECO, E. Geographic information systems for wildland fire risk mapping. Wildfire, Washington, v. 3, n. 2, p. 7 - 13, 1994.

SOARES, R. V. Incêndios florestais: controle e uso do fogo. Curitiba: FUPEF, 1985. 213 p.

STRAUBE, F. C.; URBEN-FILHO, A.; GATTO, C. A avifauna do Parque Estadual do Cerrado (Jaguariaíva, Paraná) e a conservação do cerrado em seu limite meridional de ocorrência. Atualidades Ornitológicas, Ivaiporã, v. 127, p. 29, 2005.

VETTORAZZI, C. A.; FERRAZ, S. F. B. Uso de sistemas de informações geográficas aplicados à prevenção e combate a incêndios em fragmentos florestais. Série Técnica IPEF, Piracicaba, v. 12, n. 32, p. 111 - 115, 1998. 